\title{
ICTs and Montessori for Learning Disabilities
}

\author{
https://doi.org/10.3991/ijes.v5i3.7384 \\ Eugenia G. Gkeka, Athanasios S. Drigas $\left({ }^{(}\right)$ \\ National Centre of Scientific Research "Demokritos", Athens, Greece \\ dreiit.demokritos.gr
}

\begin{abstract}
This paper concentrates on the Montessori philosophy and examines how this learning theory currently gives credence to cognitive processes of the mind, as suitable intervention used to the training of children with learning disabilities. Furthermore, Montessori's system and materials in combination with the support of new technologies as well as their implementation on various kinds of Information and Communication Technologies (ICTs) have great successes regarding the support of disability and the enhancement of learning process.
\end{abstract}

Keywords-ICTs, intervention, learning disabilities, Montessori philosophy, prepared environment.

\section{Introduction}

In this article we present an overview of representative studies of the last years (20062016) which shows how Maria Montessori's thought influences the contemporary educational theory and practice affected by technology. The paper consists of the definitions and the more important part of prominent types of learning disabilities.

Colgan reveals the epistemology of Dr. Maria Montessori's Method analyzing her philosophical ideas of sensitive education in the modern literature. Montessori's philosophy, according to the author, accumulates the various ideas of priors and contemporary educational philosophers. As a consequence, educational philosophers such as Rousseau, Spencer, Pestalozzi, Frobel, Dewey who was her contemporary, also Itard and Seguin are recalled through her method as well as Aristotle and Plato's ancient philosophies are resurrected. Specifically, Montessori philosophy is based on sensory education and she identifies with Aristotle's philosophy who pronounced in "Metaphysics": "all men by nature desire to know. An indication of this is the delight we take in our senses". This knowledge is hierarchical and is acquired through action and perception as in the case of her writing program which connects sounds to letters and learning words through their phonetic parts. Along with the training of the senses in early age and the coordinated Knowledge are included the individuality and the auto education in agreement with Aristotle. The researcher emphasizes that Montessori's process is from perception to conception based on the use of didactical materials, their choice and in relation to individual needs of the children. [1]. 
Zviel -Girshin and Rosenberg make reference to the method constructivism and present Maria Montessori as an innovator educator who based on scientific direction and namely engineering such as she had studied before studying medicine. This term is given by John Dewey (1938) years after the implementation of Montessori's approach in "Casa dei bambini" (1907). They describe the research, the design and the instruction of undergraduate software engineering course of three departments: Computer Science, Industrial Engineering and Computer Engineering. The researchers succeed to combine a new SE paradigm - Organic Knowledge using extensively ICT and preferred method called "Montessori pedagogy" [2].

Ültanır analyzes the Constructivist theory of knowledge and its founders John Dewey, Jean Piaget and Maria Montessori. Piaget's main focus of constructivism has to do with the individual and how the individual constructs knowledge. Maria Montessori and Dewey substitute traditional classrooms with new classroom models which student becomes constructor of knowledge. Constructivism as theory explains the nature of knowledge and learning based on learners' precedent experience and background knowledge. Thus, the creation of a constructivist learning environment bases on the activity of students, self observing and individual and cooperative group work. .Also, the teacher facilitates learners to formulate their own ideas, opinions and conclusions and this decentralization of the authority's teacher is one of the aspects of Montessori's work [3].

\section{$2 \quad$ Learning disabilities}

\subsection{Definitions}

Jamieson relates learning disabilities to having difficulty learning to read and write and involving the auditory, phonological, visual processing problems, spelling, speech and comprehension as well as memory and attention problems. The researcher insists on early identification and remediation which are important and the most effective approach is the multisensory education such as the Montessori Method. Hence, the appropriate remedial intervention of these learning disabilities is founded on both the Montessori prepared environment and the learning materials. The Montessori education aims at motor skills, coordination and dexterity as well as the practical life exercises which support the remediation of fine and gross motor problems, left/right discrimination problems, visual-motor and visual -spatial problems. Furthermore, sensory education is helpful and as remedial intervention for visual and auditory perception, reception, discrimination and association problems using the materials as pink tower, red rods, binomial and trinomial cubes, solid cylinders. The movable alphabet and the sandpaper letters remedy the sub-disabilities of ineffective sound-symbol association, phonological awareness and spelling problems [4].

Boyce makes reference to multisensory instruction and the Montessori's approach when the investigation of her study conducts the effectiveness of video learning game, the Quizlet application, used as learning tools on students with learning disabilities. According to Learning Disabilities Association of America (LDA), the difficulties are 
divided in three fields that include the ability of reading, writing and spelling, understanding mathematical concepts and sensory disabilities. Correspondingly, the frequent forms of learning disabilities are dyslexia, dyscalculia and visual and auditory disturbances. Afterwards, she explains the significance of the technology in the world of communication, information and learning and the methodology for the use of the Quizlet with the aim to acquisition science vocabulary, and student engagement in science activities. The participants, seven seventh grade middle school students, with troubles in listening and reading comprehension and written expression, showed increases in both science vocabulary acquisition and engagement behaviors[5].

\section{$3 \quad$ Classifications of Learning disabilities}

\subsection{Dyslexia}

Reinecke expounds on the dyslexia as the most common type of learning disability and the Montessori program as beneficial approach as well as the early intervention for these language disorders based on valid references. Especially the researcher refers: "According to the International Dyslexia Association, dyslexia is a neurobiological learning disability resulting from a deficit in the phonological component of language" and for language is responsible the left hemisphere of the brain. The sequence of Montessori's motor and sensory exercises benefits the writing and reading development and in particular it is appropriate for decoding, recognizing the words and for the reading comprehension [6].

Awes, initially explains the importance of language for the human race, as well as the development of phonemic awareness, and reading comprehension. She continues with the definition of dyslexia, the learning disability and the particular function of brain in dyslexics. Additionally, she exposes the intervention program and the benefits and effectiveness of the Montessori Method for dyslexic children. In particular, the Montessori environment introduces phonetic approach and the repeated multisensory experience (the sandpaper letters, the movable alphabet and puzzle words) with the combination of visual, auditory, and tactile learning, encourage the awareness of sounds in the age three to six. Furthermore, the activities of spoken language for the music, art, geography, etc. enrich the vocabulary and prepare the children for total reading. Besides, Montessori principles continue in the elementary classroom and through cosmic education the child learns word families and compound words. Then, in the middle school with the assistance of computers and the audio book the dyslexic child can read more actively by underlining or taking notes while listening, thereby reinforcing the content[7].

Smith explains how the great growth of Mobile Technologies, the iPad, iPhone, iPod, the iPad touch, plays a part in determining for instruction. In particular, the interactivity of the iPad, using your fingers to manipulate the screen, creates an emotional experience and enhances memory. In fact, using the iPad apps list in the dyslexia program for intervention, educators realize the effectiveness of these devices as well as the impact on learning. In the iPad list, after the favorite apps WordBingo, 
Montessori Crosswords is distinguished considering that it offers phonemic awareness, vocabulary and spelling. Also, the students acquire fluency, handwriting, written expression and comprehension [8].

\subsection{Dyscalculia}

Dyscalculia as dyslexia is a type of disorder which pertains to the deficit of ability in the mathematical concepts. Several motives such as problems in speech, visual or acoustic perception and memory indicate that a child needs to be diagnosed and after which any possible treatment could be started. Among therapies Montessori materials are suggested due to the fact that these augment levels of perception, thinking, concentration, memory, language skills as well as fundamental mathematic notions on numbers. The paper proposes computer- personalized programs used for practicing the order, the concept of numbers and of grouping numbers, understanding division as well as comparison of quantities and fraction program aimed at supporting the pedagogical program of Elementary school and Methodological Centre for Special Education in Hungary. [9].

This paper [10] underlines the importance of preschooler numeracy skills to future mathematics achievement. Furthermore it describes an experiment using a mobile tablet computer, Math Shelf which its software integrates the mathematics materials and sequence created by Maria Montessori. The games of Math Shelf, in the curriculum sequence, employ different virtual manipulatives as Montessori number rods, colored beads, and counters/dot cards, the colored and golden bead manipulatives and the Montessori hundreds' board, as well as Montessori ten numeral cards and the unit numeral cards. Finally, preschoolers who played with Math Shelf acquired significant practice of arithmetic operations and this intervention substantially increases lowincome children's number knowledge.

Waicanjo analyzes the learning difficulties of students in mathematics (dyscalculia) which cannot remember mathematical information, as well as the process in problem solving. The researcher proposes as support the use of assistive technology in order to develop and acquire the arithmetical skills .Furthermore, differential strategies are adopted by preparatory schools as Inquisitive Minds Montessori International School, also differentiated teaching methods by using ICT. The use of ICT in assisting dyscalculia students in Kenya is affected by technological software and hardware which in this study are referred to computer software and hardware [11].

\subsection{Attention-Attention Deficit Hyperactivity and coordination Disorder (ADHD) and Attention Deficit Disorder (ADD).}

Wilson analyzes the Attention Deficit Hyperactivity Disorder (ADHD) which is neurobehavioral disorder and characterized by the lack of the attention as well as by excessive movements, impulsivity, and impatience. According to current researches it is caused by the heredity of the individuals and due to environmental reasons and especially environmental toxins such as mercury, lead, and manganese. The study focuses on the intervention and the effects of the green play environment and suggests 
it as therapy. According to Montessori nature is an important factor for the child's development within a learning society [12].

Doğru establishes the efficacy of Montessori approach for the children with Attention Deficit Hyperactivity and coordination Disorder (ADHD) and Attention Deficit Disorder (ADD). The FTFK attention test was applied, using particular Montessori materials: sound boxes, binomial cubes, color tablets and tactile boards. The positive effects of Montessori materials on children's attention and concentration are obvious and according to valid references, these effects are due to the educator who acts as guide while the child corrects himself [13].

Feiner and Resnik emphasize that the movement is very important for the human development. Therefore they recommend that the combination of E-learning and social phases. This combination enhances communication and corporeal learning as the Montessori's learning with appropriate learning materials. Additionally, the researchers propose for children with ADHD who characterize by hyperactivity, inattentiveness and impulsivity, interactive technology and especially interactive boards in education because with these tools the concentration and control are achieved [14].

\subsection{Memory}

Frangou investigates the function of the brain and the short-term and long-term memory. The different experiences of the individual are stored in the short-term memory and are retrieved in long-term memory. Namely, she explains the complex procedure of the learning which is based on the memory and the important role of the different writing ways from handwriting to typing which affect memory retrieval in examination the logical memory performance of thirty-one students in Finland. Generally, the researcher highlights the benefits of handwriting in agreement with Montessori's saying: "the hands are the instruments of man's intelligence". Additionally, the use of information and communication technologies with the new media devices as new support tools reinforces the memory and assists students with learning difficulties [15].

Sabitser describes the complex mechanism of the memory system in the human brain and how the basic principles of neurodidactics (neuroscience and didactics) influence it. The researcher accentuates that the new learning data and in general the acquisition of knowledge are consolidated and stored in long-term memory with focus and concentration and not with inattention and mental stress. Also, as each brain is different, it cannot be altered in structure and development however it can be influenced by circumstances. Following Maria Montessori's principles "Help me to do it myself!" or "The teacher has to be passive so that the child can be active." these apply in ICT and computer science education classes with the aim to discover learning and educate competences [16].

$\mathrm{Hu}$ et al. examine the cognitive processing of the information based on embodied cognition and Cognitive Load Theory which as learning theory concerns with the human memory systems. Namely, the human brain consists of three mnemonic systems: the sensory input accomplished through humans' five senses, the short- term memory or limited working memory and the long-term memory and whole this mech- 
anism is compared to computer system. According to the recent researches working memory consists of a control system with two subsystems the "visuo-spatial sketchpad" and the "phonological loop" which plays a role in the language development of children. The expansion of the working memory systems involves haptic information which is referred to the touch sense as a consequence an active exploration of the environment such as the "tracing" method prompted by Montessori. Especially, the researchers explain how the cognitive development benefits from the use of tracing with fingers used in Montessori education with the sandpaper letters. Thus, children with reading difficulties touching and tracing the sandpaper letter are able to memorize the spoken and written forms of a word. This cognitive processing of the information through sensitive sense of touch is significant in the cognitive activity of daily life and it becomes important with the development of information and communication technologies (ICT) with touch devices [17], [18].

\subsection{Motor - Dyspraxia}

Kareem and Shree explain the mean of dyspraxia which involves difficulties in physical movements and their coordination. This effect is due to unreliable transmission of messages from the brain to the body. Moreover this disorder involves fine motor difficulties which every child encounters in writing, copying, cutting, coloring and reading and these along cognition were evaluated by the physician and the educationist Montessori constantly in her classroom. The researches present an experiment design which participate 30 children aged younger than 13 aged and older than 14 aged with dyspraxia in enhancing fine motor skills. The program is based on constructional several activities including ocular Motor control, hand-eye coordination, manual dexterity and sterognosis which are object's recognition only using the sense of touch. The outcomes of activity based model had a positive effect in enhancing the Fine Motor Skills of Children with Dyspraxia [19].

The experiment on multi-touch devices and particularly iPad apps for children aged between 2 to 4 years old investigates the age group which can correspond with the gestures according to motor skills developed: tap, drag/slide, free rotate, drag and drop, pinch, spread and flick. The selection of apps is crucial and one more attractive and fan is Montessori Crosswords which uses all the seven gestures. The results of experiment shows that children aged two years successfully use tap and drag/slide gestures while children aged four years and above use all seven gestures. Finally it is a very important recommendation using apps with specific gestures that could examine motor difficulties or disorders such as dyspraxia. Undeniably, this recommendation is pointing to Montessori Method and materials in a way that the motor skills are grown and motor disorders are improved [20].

Vatavu et al., present children's touch interaction on smart phones and tablets with standard gestures tap and drag and drop. The participants were children aged from 3 to 6 years, stage called preoperational according to Piaget's cognitive developmental theory as well as young adults to serve as comparison. Hence the authors recommend provision of rewards and games in order that making activities as Montessori. The experiment indicates that the children find difficulties to use mobile applications by 
reason of their abilities connected with the development of motor skills, especially with their level of finger dexterity, visual motor precision and generally the coordination of small muscles responsible for the fine movements of hands and eyes. The outcomes of the experiment point to the guidelines for designing touch-screen interfaces for small-age children e not only [21].

According to us these devices might constitute tools that could examine motor difficulties or disorders and they will probably intervene in improving these difficulties.

\section{Conclusion}

The aim of this investigation was to verify the Montessori philosophy as a learning theory which is able to support the learning process and in combination with information and communication technologies are achieved effects in order to assist the children with learning disabilities.

In particular, the Montessori philosophy has been distinguished for the meaning of constructivism, the sensitive or multisensory education and individual curriculum among various learning theories and as result it is regarded intertemporal. Definitely, the up growth of information and communication technologies is the outcome of the precedent learning theories. According to literature they contribute to a great success in the complex learning process and to the mechanism of knowledge and assist the children with disorders. The majority of the presented technologies are iPhone/ iPad educational applications and generally mobile tablet computer, the interactive technology such as interactive boards, as well as assistive technology.

To sum up, Montessori's system and materials based and created on multisensory philosophy fulfill the needs of learning disabilities in language, mathematics, reading and writing, memory, attention and motor.

\section{$5 \quad$ References}

[1] Colgan, Andrew D. "The Epistemology Behind the Educational Philosophy of Montessori: Senses, Concepts, and Choice." Philosophical Inquiry in Education 23.2 (2016): 125-140.

[2] Zviel-Girshin, Rina, and Nathan Rosenberg. "Montessori+ SE+ ICT= SEET: using SE to teach SE." Proceedings of the 5th International Workshop on Theory-Oriented Software Engineering. ACM, 2016. https://doi.org/10.1145/2897134.2897140

[3] Ultanir, Emel. "An Epistemological Glance at the Constructivist Approach: Constructivist Learning in Dewey, Piaget, and Montessori." Online Submission 5.2 (2012): 195-212.

[4] Jamieson, Natalie. The contribution of the Montessori Approach to Multisensory Approaches to Early Learning Disabilities. Diss. 2006.

[5] Boyce, Deborah Ann. "The effect of the video game Quizlet on the acquisition of science vocabulary for children with learning disabilities." (2016).

[6] Reinecke, Katherine J. "The Dyslexic Student and the Montessori Method for Early Literacy." (2015).

[7] Awes, Alison. "Supporting the Dyslexic Child in the Montessori Environment." Communications 1.2 (2012): 54.

[8] Smith, Jodie. "iLit: Using iPads for multi-sensory literacy development intervention." (2012). 
[9] Réthey-Prikkel, Brigitta, and Márta Turcsányi-Szabó. "Design and evaluation of Maths related programs for special education." Bratislava: Proceedings of EuroLogo (2007).

[10] Schacter, John, and Booil Jo. "Improving low-income preschoolers mathematics achievement with Math Shelf, a preschool tablet computer curriculum." Computers in Human Behavior 55 (2016): 223-229. https://doi.org/10.1016/j.chb.2015.09.013

[11] Waiganjo, Sarah. Using Ict To Assist Dyscalculia Students Situation Analysis For Primary Schools In Kenya, A Case Study Of Starehe District Nairobi County. Diss. University of Nairobi, 2013. Chapter one: Introduction.

[12] Wilson, Melissa R. "Green Play: Restorative Neurobehavioral Effects on ADHD Children." (2014).

[13] Dogru S. Sunay Yildirim. "Efficacy of Montessori education in attention gathering skill of children." Educational Research and Reviews 10.6 (2015): 733.

[14] Feiner, Franz, and Mojca Resnik. "E-learning needs encounter and corporeal learning." Distance learning, simulation and communication 2011 (2011): 75.

[15] Frangou, Satu-Maarit. The power of writing hands: logical memory performance after handwriting and typing tasks with Wechsler Memory Scale revised edition. MS thesis. $\mathrm{fi}=$ Lapin yliopisto| en= University of Lapland|, 2016.

[16] Sabitzer, Barbara. "Neurodidactics: Brain-based Ideas for ICT and Computer Science Education." International Journal of Learning 18.2 (2011).

[17] Hu, Fang-Tzu, Paul Ginns, and Janette Bobis. "Getting the point: tracing worked examples enhances learning." Learning and Instruction 35 (2015): 85-93. Chapter One-Three https://doi.org/10.1016/j.learninstruc.2014.10.002

[18] Hu, Fang-Tzu, Paul Ginns, and Janette Bobis. "Does Tracing Worked Examples Enhance Geometry Learning?." Australian Journal of Educational \& Developmental Psychology 14 (2014): 45-49.

[19] Kareem, Jacqueline. "Effectiveness of Activity Based Program in Enhancing Fine Motor Skills of Children with Dyspraxia." Scholedge International Journal of Multidisciplinary \& Allied Studies ISSN 2394-336X 2.5 (2015): 76-84.

[20] Aziz, Nor Azah Abdul, et al. "Selection of touch gestures for children's applications." Science and Information Conference (SAI), 2013. IEEE, 2013.

[21] Vatavu, Radu-Daniel, Gabriel Cramariuc, and Doina Maria Schipor. "Touch interaction for children aged 3 to 6 years: Experimental findings and relationship to motor skills." International Journal of Human-Computer Studies 74 (2015): 54-76. https://doi.org/10.1016/j.ijhcs.2014.10.007

\section{Authors}

Athanasios Drigas is a Research Director at IIT-N.C.S.R. Demokritos. He is the Coordinator of Telecoms Lab and founder of Net Media Lab since 1996. From 1990 to 1999 he was the Operational manager of the Greek Academic network. He has been the Coordinator of Several International Projects, in the fields of ICTs, and eservices (e-learning, e-psychology, e-government, e-inclusion, e-culture etc). He has published more than 270 articles, 7 books, 25 educational CD-ROMs and several patents. He has been a member of several International committees for the design and coordination of Network and ICT activities and of international conferences and journals.

Eugenia Gkeka is a foreign language teacher. She collaborates also with N.C.S.R. 'Demokritos', Institute of Informatics and Telecommunications, Telecoms Lab - Net Media Lab, Athens, Greece.

Article submitted 04 July 2017. Published as resubmitted by the authors 15 September 2017. 